\title{
Electronic cigarettes and lung toxicity
}

\author{
Terrance Rodrigues MBA, Eric L Deal MS, Kenneth Nugent MD, Drew Payne DO
}

\begin{abstract}
The use of electronic cigarettes (e-cigarettes) in the United States has steadily increased since their introduction into the market in 2007. These devices deliver nicotine through the vaporization of a liquid which contains a vehicle (propylene glycol or glycerin), artificial flavoring, and nicotine. The combustion of these liquids creates a vapor containing particulates, multiple chemicals, and nicotine. The long-term safety of these products is unknown. Studies in healthy, non-smoking volunteers and smokers with no clinical pulmonary disease have demonstrated that the inhalation of e-cigarette vapor has minimal short-term effects on pulmonary function. The exposure of cell cultures to e-cigarette liquid or aerosols has been shown to reduce cell viability, induce cytokine production, and cause oxidative stress. The exposure of animals (mice and rats) to e-cigarette aerosols induces inflammatory responses in the lungs and delays the clearance of bacterial and viral challenges. There are a small number of case reports of patients developing acute pulmonary toxicity following the use of e-cigarettes. Two patients have developed lipoid pneumonia following the use of e-cigarettes for 3 and 7 months. Finally, several studies suggest that patients with chronic lung disease who switch from tobacco cigarettes to e-cigarettes can have improvement in lung function (asthmatics) and a reduction in the number of exacerbations (chronic obstructive pulmonary disease). Clearly, the public and the medical profession need more information about the long-term complications associated with the use of e-cigarettes and their benefit in smoking cessation efforts.
\end{abstract}

Keywords: electronic cigarettes, pulmonary toxicity, pulmonary function, animal models

\section{INTRODUCTION}

Since their introduction in 2007 , electronic cigarettes (e-cigarettes) have increased in popularity in the United States. These devices typically include an aerosol generator, a flow sensor, battery, and a solution cartridge of variable composition containing

Corresponding author: Drew Payne

Contact Information: Drew.payne@ttuhsc.edu

DOI: $10.12746 /$ swrccc.v5i19.394 a carrier solution (propylene glycol or vegetable glycerin), artificial flavoring, and nicotine. ${ }^{1,2}$ Recent surveys have reported that ever use of e-cigarettes among adults has increased from $1.8 \%$ in 2010 to $13 \%$ in 2013 , and current use has increased from $0.3 \%$ to $6.8 \%$ over the same time period. ${ }^{3}$ Due to this increase in use, clinicians should be aware of the potential effects e-cigarettes have on the respiratory system. In this review we consider four main topics: 1) The effects of e-cigarettes on pulmonary function tests; 2) Pulmonary toxicity related to e-cigarettes based on case reports; 3) The effects of e-cigarettes on cells using in vitro studies; 4) The effects of e-cigarettes in animal models. 


\section{METHODS}

The PubMed database and Google Scholar were searched using the MeSH terms electronic cigarettes combined with (AND) drug-related side effects and adverse reactions, lung diseases, case reports (publication type), animal models, or pulmonary function tests.

\section{Discussion}

\section{E-CIGARETTES AND LUNG FUNCTION}

The vapor generated by e-cigarettes includes nicotine and multiple other chemical compounds. Nicotine has a direct effect on vagal afferent nerves in the airways and causes cough and bronchoconstriction. The various chemicals present in e-cigarette vapor can cause direct irritant effects on cholinergic receptors in the airways. Therefore, studies have tried to determine whether or not e-cigarettes cause changes in pulmonary function in non-smokers or traditional cigarette smokers and whether or not nicotine is a key component in any observed response. Three recent studies measured pulmonary function before and after e-cigarette smoking. Flouris et al enrolled 30 subjects in two cohorts; one cohort included fifteen smokers who smoked greater than fifteen cigarettes a day and the other cohort included fifteen never smokers. ${ }^{4}$ Smokers were exposed to e-cigarette vapor consistent with the level of nicotine found in two traditional cigarettes, while never smokers were exposed to passive levels of e-cigarette vapor consistent with that of a bar/restaurant with e-cigarette use. Spirometry was measured before, immediately after, and one hour post-exposure. Neither cohort experienced statistically significant post-exposure changes in PFTs $\left(\mathrm{FEV}_{1}, \mathrm{FVC}, \mathrm{FEV}_{1} / \mathrm{FVC}\right.$, or $\left.\mathrm{FEF}_{25-75 \%}\right)$. Ferrari et al studied the effect of nicotine free e-cigarettes. ${ }^{5}$ Twenty subjects were enrolled in two cohorts; the first consisted of ten smokers with a minimum five packyear history and the second included ten never smokers. ${ }^{5}$ Each cohort was randomized with cross-over; five subjects within each group smoked nicotine free e-cigarettes first and then two traditional cigarettes
24 hours later. The other five subjects in the cohorts smoked the traditional cigarette first and then the nicotine free e-cigarettes. Pulmonary function was measured five minutes before and immediately after smoking for five minutes. Results showed that e-cigarettes had no significant effect on FeCO or FeNO in either non-smokers or smokers. Smokers who used a nicotine free e-cigarette did show a significant decrease in $\mathrm{FEV}_{1}$ and $\mathrm{FEF}_{25-75 \%}$, while in non-smokers there were no significant changes in spirometry. Vardavas et al studied the effects of e-cigarettes in 30 smokers with no clinical pulmonary disease (age 19-56, 14 males). ${ }^{6}$ Use of an e-cigarette ad lib for 5 minutes caused an immediate reduction in FeNO $(16 \%)$ and increases in airway resistance measured by impulse oscillometry. There were no changes in FeNO or flow resistance in 10 subjects randomly selected from the main group who handled an e-cigarette but did not have exposure to the vapor. These studies demonstrate that there are no short-term changes in spirometry in e-cigarette users who are never smokers. However, smokers may have a slight decrease in lung function and an increase in peripheral airway resistance when exposed to e-cigarette vapor.

Polosa et al prospectively followed 18 patients with asthma who were former cigarette smokers who switched to e-cigarettes. ${ }^{7}$ These patients had had asthma for an average of 20 years and had smoked approximately 20 pack-years. There was a significant reduction in the use of conventional cigarettes in all e-cigarette users. At 6 months the $\mathrm{FEF}_{25-75 \%}$ increased, and the asthma control questionnaire scores increased. At 12 months the $F E V_{1}, F V C$, $\mathrm{FEF}_{25-75 \%}$, asthma control questionnaire, and methacholine responsiveness all improved. There was no difference in the number of exacerbations over twelve months. This study demonstrated that chronic asthmatics can have improved pulmonary function tests and symptoms scores when switching from conventional tobacco cigarettes to e-cigarettes.

Polosa and colleagues also performed a retrospective study of patients with COPD who switch to e-cigarettes. ${ }^{8}$ This study demonstrated that these patients had a reduction in the frequency of acute 
exacerbations over 12 month and 24 month periods. In addition, dual users who reduced the amount of conventional tobacco cigarette smoking also had a reduction in the frequency of acute exacerbations. ${ }^{8}$

To date, there is no information on the long-term effects of e-cigarettes on lung function in never smokers who adopt exclusive e-cigarette use. There is limited information in patients with lung disease, such as asthma or COPD. Long-term prospective studies in current e-cigarette users are needed to determine whether or not these devices affect lung function; however, these studies may be difficult to organize as many e-cigarette smokers are dual users.

\section{E-CIGARETTES AND LUNG TOXICITY: CASE REPORTS}

Significant exposure to the primary ingredient of the e-liquid, propylene glycol, is generally considered safe by the FDA but can cause irritation to the upper and lower respiratory tract mucosa. In addition, the flavoring chemicals in e-cigarettes, especially sweet or cinnamon e-liquid, can contain diacetyl, a compound linked to respiratory injury. ${ }^{9}$ The long term effects of exposure are unknown, and documented acute adverse effects on the lungs from e-liquid exposure have been limited to infrequent case reports and abstracts (Table). Three individual case reports have described a temporal association between subacute bronchiolitis, pleuritic chest pain with associated bilateral pleural effusions, and acute hypersensitivity pneumonitis with the use of e-cigarettes. The symptoms and chest $x$-rays in each case returned to baseline after e-cigarette cessation. ${ }^{10-12} \mathrm{~A}$ case of eosinophilic pneumonia which developed one hour after smoking an e-cigarette has been reported. This patient was treated with antibiotics and corticosteroids and improved. ${ }^{13}$ These four cases developed pulmonary toxicity after relatively brief use of e-cigarettes (1 hour to 7 days). Two patients have developed lipoid pneumonia attributed to the glycerin containing solution used in e-cigarettes, and both patients' symptoms improved with cessation of e-cigarettes. ${ }^{14,15}$ These two cases developed toxicity following more prolonged use of e-cigarettes (3 months, 7 months).

In summary, these case reports point to the unpredictable and potentially serious side effects associated with e-cigarette use. However, the information in these case reports is limited. There is no information on baseline lung function prior to presentation, smoking history is often incomplete, and the patients developed different clinical disorders, involving both airways and alveolar spaces. Therefore, the contribution of

Table Case reports with lung toxicity

\begin{tabular}{|l|l|l|l|l|l|}
\hline $\begin{array}{l}\text { Age } \\
\text { Gender }\end{array}$ & $\begin{array}{l}\text { Smoking } \\
\text { History }\end{array}$ & $\begin{array}{l}\text { Duration of } \\
\text { E-cig Use }\end{array}$ & Presentation & Diagnosis & Treatment/ Outcome \\
\hline $60 \mathrm{M}^{10}$ & $\begin{array}{l}\text { Not } \\
\text { reported }\end{array}$ & $\begin{array}{l}\text { Not } \\
\text { reported }\end{array}$ & Weakness and cough & $\begin{array}{l}\text { Hypersensitivity } \\
\text { inhalation injury }\end{array}$ & $\begin{array}{l}\text { Resolution with abstinence } \\
\text { from e-cigarette }\end{array}$ \\
\hline $43 \mathrm{M}^{11}$ & 45 pack yr & $\begin{array}{l}4 \text { weeks total; } \\
\text { SOB after 1 week }\end{array}$ & Cough and SOB & $\begin{array}{l}\text { Subacute bronchial } \\
\text { toxicity }\end{array}$ & $\begin{array}{l}\text { Resolution with abstinence } \\
\text { from e-cigarette }\end{array}$ \\
\hline $42 \mathrm{~F}^{14}$ & $\begin{array}{l}\text { Not } \\
\text { reported }\end{array}$ & 7 months & $\begin{array}{l}\text { Dyspnea and } \\
\text { productive cough }\end{array}$ & $\begin{array}{l}\text { Exogenous Lipoid } \\
\text { pneumonia }\end{array}$ & $\begin{array}{l}\text { Resolution with abstinence } \\
\text { from e-cigarette }\end{array}$ \\
\hline $31 \mathrm{~F}^{15}$ & Not reported & 3 months & Dyspnea and cough & $\begin{array}{l}\text { Exogenous Lipoid } \\
\text { pneumonia }\end{array}$ & $\begin{array}{l}\text { Resolution with abstinence } \\
\text { from e-cigarette }\end{array}$ \\
\hline $43 \mathrm{M}^{12}$ & $\begin{array}{l}\text { Smoker \# } \\
\text { pack-yr } \\
\text { Not reported }\end{array}$ & 3 days & $\begin{array}{l}\text { SOB and pleuritic } \\
\text { chest pain }\end{array}$ & $\begin{array}{l}\text { Pneumonia and } \\
\text { bilateral pleural } \\
\text { effusions }\end{array}$ & $\begin{array}{l}\text { Resolution with abstinence } \\
\text { from e-cigarette }\end{array}$ \\
\hline $20 \mathrm{M}^{13}$ & Not reported & 1 hour & SOB & $\begin{array}{l}\text { Acute eosinophilic } \\
\text { pneumonia }\end{array}$ & $\begin{array}{l}\text { Resolution with abstinence } \\
\text { from e-cigarette }\end{array}$ \\
\hline
\end{tabular}


pre-existing lung disease and prior cigarette smoking is uncertain. In addition, the unregulated production of e-cigarette liquid creates situations in which undisclosed and possibly toxic substances are included in the e-liquid.

\section{E-CIGARETTES AND IN VITRO TOXICITY?}

The effects of e-cigarettes at the cellular level have not been well studied. The aerosol generated from e-cigarettes typically contains variable artificial flavors, a carrier solution, and nicotine. Leigh et al explored the effect of artificial flavors on the metabolic activity, as measured by neutral red uptake assay; viability, as measured by trypan blue assay; and the inflammatory cytokine activity, as measured using enzyme-linked immunosorbent assay kits, of human bronchial cells. ${ }^{16}$ Of five artificial flavored aerosols tested, three significantly decreased cell viability and metabolic activity when compared to air controls, while a fourth significantly decreased metabolic activity but had no significant effect on cell viability and the fifth had no effect on either viability or metabolic activity. Two flavors increased the levels of inflammatory cytokines when compared to air controls (IL-1 $1 \beta$, IL-10, CXCL1, CXCL2 CXCL10 and IL-6, CXCL1 CXCL2, respectively). ${ }^{16}$

Human bronchial cells were exposed to carrier solutions of propylene glycol only, vegetable glycerin only, and a 50/50 mixture of propylene glycol and vegetable glycerin. Each carrier solution resulted in a significant decrease in cell viability but only two solutions, the 50/50 mixture of propylene glycol and the vegetable glycerin showed a significant decrease in cell metabolic activity. Each carrier solution resulted in a significant increase in the inflammatory cytokine IL-10 with variable increases in the other cytokines tested (IL-1 $\beta$, IL-6, IL-10, CXCL1, CXCL2 and CXCL10). ${ }^{16}$ In a study by Scheffler et al human bronchial epithelial cells also showed reduced cell viability and higher oxidative stress when exposed to propylene glycol versus clean air. ${ }^{17}$

Leigh et al compared the effects of five nicotine concentrations on human bronchial cell viability and metabolic activity with air controls. No significant differences were observed in metabolic activity and cell viability. When cells were exposed to $18 \mathrm{mg} / \mathrm{mL}$ of nicotine, there was a significant decrease in IL-1 $\beta$, CXCL1 and CXCL2 versus air controls but when exposed to $24 \mathrm{mg} / \mathrm{mL}$ a significant increase in IL-6 was found. ${ }^{16}$ Differing results were found in a study by Schweitzer et al. Rat lung endothelial cells were exposed to two separate nicotine-containing e-cigarette solutions. ${ }^{18}$ Each caused a dose dependent cellular injury seen by decreased barrier function. One of the two solutions also induced similar dysfunction in its nicotine free variety, suggesting dysfunction is only partially nicotine dependent. Vaporization of the solutions caused similar, but less potent dose dependent decreases in function. Dose dependent loss of endothelial function was also seen in human lung endothelial cells in both solution and vaporized forms, although a less potent effect was seen in the vaporized form. ${ }^{18}$ Mixed results were seen in a study by Scheffler et al. Two cell lines of human bronchial endothelial cells were exposed to two varieties of one e-cigarette aerosol, one variety contained nicotine and the other was nicotine free. One cell line showed similar results independent of nicotine concentration while the other showed a significant increase in oxidative stress but no difference in cell viability when compared to clean air. ${ }^{17}$

These in vitro studies suggest that artificial flavoring has variable negative effects on both cell viability and metabolic activity and results in an increase in inflammatory cytokine production but due to the wide variety of flavors and variability in composition, it is difficult to draw conclusions on flavorings as a whole. Carrier solutions showed increases in inflammatory cytokines while studies of nicotine's effects on cell viability, metabolic function, and inflammatory cytokine production had differing results. Overall, these studies show the components of the aerosol generated by e-cigarettes have potentially harmful effects in vitro and need to be studied further.

\section{E-CIGARETTE EFFECTS IN ANIMAL MODELS}

Studies using animal models and e-cigarette vapor can provide more precise information about 
in vivo events. Lerner et al exposed mice to either room air or e-cigarette aerosols for 5 hours per day for three consecutive days. ${ }^{19}$ The mice then underwent bronchoalveolar lavage to measure cytokine production and lung homogenization to measure changes in glutathione levels. Bronchoalveolar lavage fluid collected 24 hours after the last exposure had increased levels of M CP-1 (a potent macrophage chemotactic cytokine) and IL-6. Lung lysates had reduced glutathione levels after exposure to e-cigarettes. This study indicates that short-term exposure increases inflammatory cytokines in bronchoalveolar spaces and causes oxidative stress with reduced glutathione levels. Werley et al exposed rats to low-dose, mid-dose, and high-dose aerosols from e-cigarette formulations for 90 days. ${ }^{20}$ There was a dose-dependent increase in bronchoalveolar lavage fluid lactate dehydrogenase levels, total protein levels, the number of alveolar macrophages, the number of neutrophils, and lung weight at 90 days. This effect was largely explained by the vehicle control (a mixture of glycerin and propylene glycol) and resolved after a 42 days washout period. This study would suggest that the chemical constituents in e-cigarettes can cause both inflammation and lung injury with increased capillary permeability. Sussan et al exposed mice to e-cigarette vapor for 1.5 hours twice daily for 2 weeks. ${ }^{21}$ This exposure resulted in oxidative stress and macrophage mediated inflammation. These mice had impaired clearance of bacterial challenges $\left(10^{5}\right.$ Streptococcus pneumoniae using an intranasal route) secondary to decreased phagocytosis by macrophages. In addition, these mice had impaired clearance of influenza A with an increase in lung viral titers, in morbidity (weight loss), and in mortality.

In summary, these animal model studies demonstrate that short-term exposure to aerosols from e-cigarettes can induce inflammatory responses in murine lungs and cause oxidative stress. In addition, these exposures alter bacterial clearance and viral clearance in the lungs. The vehicle in e-cigarettes may cause these toxic effects.

\section{Conclusions}

Combustion of the liquid in e-cigarettes creates a vapor which includes multiple small particulates, chemicals, and nicotine. This exposure does not appear to cause any acute changes in pulmonary function in healthy non-smokers. However, exposure does appear to increase peripheral resistance in smokers. There is no information on adverse effects associate with long-term regular use of e-cigarettes. There are several case reports which suggest that these devices can be associated with acute lung injury. In vitro studies indicate that the aerosol from e-cigarettes can cause cell injury. In vivo studies demonstrate that these aerosols can induce inflammatory responses in murine lungs and can alter host defenses with reduced clearance of bacterial and viral pathogens. Studies on the long-term effect of e-cigarettes will need to consider liquid composition, the frequency of smoking, the presence of underlying clinical or subclinical lung disease, and idiosyncratic responses. The best approach to the studies will likely involve longitudinal cohort studies which include healthy controls with no smoking history, e-cigarette users, tobacco cigarette smokers, and dual users. Until this information is available consumers and physicians should not conclude that these devices are safe. If viewed as smoking cessation/reduction devices, e-cigarettes may have a role in harm reduction. If used in smoking cessation programs, then regulation is needed to assure the composition of e-liquid meets safety standards.

Article citation: Rodrigues T, Deal E L, Nugent K, Payne D. Electronic cigarettes and lung toxicity. Southwest Respiratory and Critical Care Chronicles 2017; 5 (19): 16-21

From: Department of Internal Medicine, Texas Tech University Health Sciences Center, Lubbock, TX

Submitted: 3/22/2017

Accepted: $4 / 14 / 2017$

Reviewer: MA Orellana-Barrios MD

Conflicts of interest: none

\section{REFERENCES}

1. Brown CJ, Cheng JM. Electronic cigarettes: product characterisation and design considerations. Tob Control 2014;23 Suppl 2:ii4-10. 
2. Orellana-Barrios MA, Payne D, Medrano-Juarez RM, Yang S, Nugent K. Electronic Cigarettes for Smoking Cessation. Am J Med Sci 2016;352:420-6.

3. McMillen RC, Gottlieb MA, Shaefer RM, Winickoff JP, Klein JD. Trends in Electronic Cigarette Use Among U.S. Adults: Use is Increasing in Both Smokers and Nonsmokers. Nicotine Tob Res 2015;17:1195-202.

4. Flouris AD, Chorti MS, Poulianiti KP, et al. Acute impact of active and passive electronic cigarette smoking on serum cotinine and lung function. Inhal Toxicol 2013;25:91-101.

5. Ferrari M, Zanasi A, Nardi E, et al. Short-term effects of a nicotine-free e-cigarette compared to a traditional cigarette in smokers and non-smokers. BMC Pulm Med 2015;15:120.

6. Vardavas CI, Anagnostopoulos N, Kougias M, Evangelopoulou V, Connolly GN, Behrakis PK. Short-term pulmonary effects of using an electronic cigarette: impact on respiratory flow resistance, impedance, and exhaled nitric oxide. Chest 2012;141:1400-6.

7. Polosa R, Morjaria J, Caponnetto P, et al. Effect of smoking abstinence and reduction in asthmatic smokers switching to electronic cigarettes: evidence for harm reversal. Int J Environ Res Public Health 2014;11:4965-77.

8. Polosa R, Morjaria JB, Caponnetto P, et al. Evidence for harm reduction in COPD smokers who switch to electronic cigarettes. Respir Res 2016;17:166.

9. Allen JG, Flanigan SS, LeBlanc M, et al. Flavoring Chemicals in E-Cigarettes: Diacetyl, 2,3-Pentanedione, and Acetoin in a Sample of 51 Products, Including Fruit-, Candy-, and Cocktail-Flavored E-Cigarettes. Environ Health Perspect 2016;124:733-9.

10. Atkins G. Acute inhalational lung injury related to the use of electronic nicotine delivery system (ENDS). Chest 2015; 148 (4): doi: 10.1378/chest.2281610 (abstract).

11. Hureaux J, Drouet M, Urban T. A case report of subacute bronchial toxicity induced by an electronic cigarette. Thorax 2014;69:596-7.
12. Moore K, Young H, Ryan M. Bilateral pneumonia and pleural effusions subsequent to electronic cigarette use. Open Journal of Emergency Medicine2015:18-22.

13. Thota D, Latham E. Case report of electronic cigarettes possibly associated with eosinophilic pneumonitis in a previously healthy active-duty sailor. J Emerg Med 2014;47:15-7.

14. McCauley L, Markin C, Hosmer D. An unexpected consequence of electronic cigarette use. Chest 2012;141:1110-3.

15. Modi S, Sangani R, Alhajhusain A. Acute lipoid pneumonia secondary to E-cigarettes use: an unlikely replacement for cigarettes. Chest 2015; 148 (4): doi: 10.1378/chest.2274860 (absrtract).

16. Leigh NJ, Lawton RI, Hershberger PA, Goniewicz ML. Flavourings significantly affect inhalation toxicity of aerosol generated from electronic nicotine delivery systems (ENDS). Tob Control 2016;25:ii81-ii7.

17. Scheffler S, Dieken H, Krischenowski O, Förster C, Branscheid D, Aufderheide M. Evaluation of E-cigarette liquid vapor and mainstream cigarette smoke after direct exposure of primary human bronchial epithelial cells. Int J Environ Res Public Health 2015;12:3915-25.

18. Schweitzer KS, Chen SX, Law S, et al. Endothelial disruptive proinflammatory effects of nicotine and e-cigarette vapor exposures. Am J Physiol Lung Cell Mol Physiol 2015;309:L175-87.

19. Lerner CA, Sundar IK, Yao H, et al. Vapors produced by electronic cigarettes and e-juices with flavorings induce toxicity, oxidative stress, and inflammatory response in lung epithelial cells and in mouse lung. PLoS One 2015;10:e0116732.

20. Werley MS, Kirkpatrick DJ, Oldham MJ, et al. Toxicological assessment of a prototype e-cigaret device and three flavor formulations: a 90-day inhalation study in rats. Inhal Toxicol 2016;28:22-38.

21. Sussan TE, Gajghate S, Thimmulappa RK, et al. Exposure to electronic cigarettes impairs pulmonary anti-bacterial and anti-viral defenses in a mouse model. PLoS One 2015;10:e0116861. 